\title{
Children's Virtual Worlds and Friendships during the covid-19 Pandemic
}

\author{
Visual Technologies as a Panacea for Social Isolation
}

\author{
Gloria Quinones \\ Faculty of Education, Monash University, Frankston, Australia \\ gloria.quinones@monash.edu
}

\author{
Megan Adams \\ Faculty of Education, Monash University, Clayton, Australia \\ megan.adams@monash.edu
}

\begin{abstract}
From March 2020 in Australia, the COviD-19 pandemic resulted in regulations for social distancing, which meant that students were homeschooled. Social distancing exponentially increased the exposure of most young children to digital technology such as touchscreens (iPads) and digital flip cameras. This study focuses on two sevenyear-old children who maintain their friendship during COVID-19 by imaginary performances and playing virtual games. A cultural-historical approach is used in the study to analyze the children's experience as they connect through virtual worlds and build imaginary spaces, contributing to sustaining their relationship during challenging times. Findings indicate that the children built a collective social situation of development integrating sophisticated imaginary, real and virtual worlds. The children's perspective - their motive orientations and intentions towards a new social situation provided new opportunities for learning in a virtual imaginary world. The combination of a real, an imaginary and a virtual world supported the children to experience a range of emotions including joyous moments, empathy and attunement as they encouraged each other to participate.
\end{abstract}

\section{Keywords}

visual technologies against social isolation - friendships - virtual worlds - virtual games - imaginary performances - COVID-19 
- This article is part of the special topic 'Visual Technologies as a Panacea for Social Isolation', edited by Rene Novak.

\section{Introduction}

Lockdowns and social distancing during the pandemic have created changes in everyday lives. Children have been actively encouraged to spend increasing amounts of time with devices and to engage with digital technology because they now receive online schooling and have limited contact with people outside their immediate family. Before the recent surge of online connectivity resulting from the COVID-19 global pandemic, there was concern raised about the lack of quality and nationally representative data reporting on children's use of the internet and the consequences of this use (Kardefelt-Winther, Livingstone, \& Saeed, 2019). There was also a sense of moral panic surrounding young children's screen time and use (Walker, Hatzigianni, \& Danby, 2018). However, these concerns have been suspended because of the CoviD-19 pandemic. The internet, apps, social media and the use of digital technologies have rapidly become an integral part of most children's lives (Swist, Collin, McCormack, \& Third, 2015). During the COVID-19 pandemic, the social distancing requirements have meant that most children's interactions outside the family unit have shifted online. Although there are studies of children ten years and older forming and maintaining friendships online (Davies, 2012; Sheer, 2011), there are few studies of children younger than ten years of age that examine the ways they participate online to maintain friendship.

In kindergarten settings, iPads have enabled new learning that was not possible before, providing children with the ability to playfully explore and make meaning together (Yelland \& Gilbert, 2018). iPads can be both a motive for learning and playing and are digital tools used in educational settings (Saluyami, Fleer \& Chapman, 2018). Teachers can create a positive spirit of competition and engagement between peers, alongside opportunities for peers to help each other (Saluyami, et al., 2018). Children are familiar with the use of technology, for example, apps like Our Story, provide children opportunity to creatively build on previous experiences and to explore and engage in imaginative meaning making; apps also provide children with the ability to document their own stories (Canning, Payler, Horsley \& Gomez, 2017). However, more research is needed to better understand technology and the role of teachers (adults) in implementing the use of tablets in the preschool setting (Furma, De Angelis, Prost \& Taylor, 2019). 
There are an increasing number of studies that consider preschool age children and digital technology integration in relation to learning in academic fields such as geography (Danby, Davidson, Ekberg, Breathnach, \& Thorpe, 2016) and science (Furman, De Angelis, Dominguez Prost, \& Taylor, 2019). Various studies have also examined the types of devices or apps (e.g. touchscreen devices including iPads) that have become part of young children's everyday experiences (Cao, 2020). Kewalramani and Havu-Nuutinen (2019) provide insights into ways teachers embed digital devices into play-based programs with children under the age of four. From a broader pedagogical perspective, Fleer (2020) analyzes digital pop-up pedagogies, where teachers create a short-term activity with a digital device, and argues that new pedagogies are required to support young children in the technological space. Studies examining the use of digital technologies in children's learning are based in either early childhood centres or lower primary schools.

Fan and Yost (2019) provides a different perspective to the studies reviewed, and argues that parents' busy schedules mean that traditional ways of communicating with their child's teacher are inadequate. Their study reported that parents and teachers in early childhood are more frequently adopting social media tools as a way of communicating with each other. However, the current study is novel in this body of research because it examines the integration of digital technology into everyday practices of children under ten years of age to maintain friendships when face-to-face contact is not possible.

There are a growing number of studies with children younger than eight years of age that examine the way technology can be used as a tool for social and emotional learning (Whitehead, 2017). Studies are situated in the everyday life of family politics that surround digital social negotiations (Aarsand \& Aronsson, 2009). Bjork-Willen and Aronsson, (2014) in their study of young children negotiating digital games found that children learn about social competence from each other as they play games together in the preschool, and can organise, evaluate and understand the technicalities of game-play. Yet, negotiating these spaces with face to face contact in the preschool or school is different to maintaining friendship over a prolonged period of time during lockdown.

Contemporary literature provides diverse studies focused on friendship in early childhood education. Seminal works by leaders in the field (see Corsaro 1985; Corsaro and Monlinari 2000; Dunn, 2004; Theobald, 2017) provide a lens into the lives of children as they interact and establish friends and friendships mainly in school or early childhood settings. Corsaro's (1985) work has been significant in understanding children's friendships and how children develop 
peer cultures. Corsaro (1985) explains how children's peer cultures relate to activities and values that are shared collectively. Rizzi \& Corsaro, (1995) found that friendships support young children to organise and adapt to their social worlds. Friendships enable collaborative problem solving in relation to psychosocial concerns (Rizzi \& Corsaro, 1995).

This work is extended by Adams and Quinones (2020) who argue that creating environments across the home and school or early childhood settings enables children the time and space to develop friendships which contributes to their social and emotional development. Yet, Kiesner, Kerr and Stattin (2004) indicate that the identification of friendships between young children is often a challenging task, as children move groupings depending upon the interest of the moment. During the CoviD-19 pandemic, the social distancing requirements in Victoria, Australia meant that most children's interactions outside the family unit shifted online. We argue that digital technology is a tool that contributes to and creates peer cultures and the development of friendships. COVID-19 provided time and space for digital connections between peers to be further developed (Quinones \& Adams, 2020).

Social relationships are the foundation for children's learning and development as they participate in their particular culture (Vygotsky, 1998). For children, the pathways to forming friendships begin either in their family, their immediate neighbourhood or at school, with parents and teachers playing a pivotal role in providing support and arranging playdates (Adams \& Quinones, 2020). However little research has explored how children engage with digital technology with friends in different contexts. The aim of this study is to explore the ways children use digital technology to support and sustain their friendships, and the content of these interactions. Using a cultural-historical approach, the current study extends the literature to focus on children who maintain their friendship during CoviD-19.

\section{Theoretical Framework}

The cultural-historical theoretical perspective has its origins in understanding young children's learning and development within their social situation (Vygotsky, 1998). An integral part of young children's social situation of development is the imaginary play that they enter (Vygotsky, 1966). The social situation of development is a concept explained by Vygotsky (1998) that focuses on the child's relation to reality, and is positioned within a child's psychological age period rather than in the child's chronological age. The social 
situation of development determines "wholly and completely the forms and the path along which the child will acquire ever newer personality characteristics, drawing them from the social reality as from the basic source of development, the path along which the social becomes the individual" (p. 198). A basic tenet within the social situation of development is understanding the process of developing social relationships. One of the most important types of these relationships is friendship, the focus of the current study.

Hedegaard and Fleer (2008) elaborate on the notion of the child's social situation of development by investigating participation in different institutions (e.g. home and school). According to Hedegaard (2020), the child's social situation changes as the child moves into new institutions as a result of unique institutional practices, traditions and values, and of what the child brings to the situation. It is well known that families create conditions and social situations for children's play and development. Fleer (2020) explains how a collective social situation of development involves family attunement and the creation of developmental conditions for children's engagement in higher forms of play such as games with rules. Playing games collectively involves participating and following rules, as well as the attunement of the participants in supporting children's play. Recent work suggests that the child's social situation of development is important, particularly while learning to cooperate, resolve conflicts and interact socially (Adams \& Quinones, 2020). Thus, it is important to examine the everyday life of children and their perspectives. Thus, children's perspectives involve capturing children's intentions (Hedegaard, 2020).

The child's perspective relates to the 'child's orientation in the world interacts [... with the effects of the] forces from the surrounding world on the child [... and] these forces have to be located in the activity settings that the child participates in' (Hedegaard, 2020, p. 5). Various activities (e.g. homework) direct the child's attention to different objects or demands according to the everyday structures of the child's day. Hedegaard (2020) explains that parents play an important role in shaping children's lives and the futures of their children, thus they create conditions for different activities.

Children develop motive orientations and engage with activities, they support and/or oppose activities by putting forward their own demands and intentions (Hedegaard, 2020). The child's perspective involves paying attention to the intentions and intentional actions of other children as they participate in activities (Hedegaard, 2020). The activities in which children participate are not a reproduction of a previous experience but a creative reworking of previous experiences (Vygotsky, 2004). In this understanding of imagination, 
Vygotsky (2004) explains that imagination is an important aspect of cultural life and is manifested in children's creativity and play. First, imagination and reality are based on previous experiences. A person's experience is broadened when they imagine; there is a double and "mutual dependence between imagination and experience" (Vygotsky, 2004, p. 17). Experiences involve feelings and emotions: "emotions influence imagination, in other cases imagination influences emotion" (Vygotsky, 2004, p. 19). The reciprocal relationship between imagination and emotion comes to the fore in children's face-to-face play; however, we know little of how play, imagination and emotion is transferred to the virtual world.

Play is a collective activity where participants create imaginary situations, and formulate rules and roles (Kravtsov \& Kravtsova, 2010; Vygotsky, 1966). In relation to imagination and play, Kravtsov and Kravtsova (2010) discuss the different positions children adopt when playing, for example, they can be inside and outside the play activity. When children play, for example hospital play, they adopt the role of a patient (inside the play activity) and enjoy or direct the play (outside the play activity). The positions include director's play, which provides the opportunity for creating a plot to control a play situation; image play, which involves the child identifying with a particular role; role play, which involves creating an imagined plot by assuming different roles. In addition, rules games also involve adhering to rules and having willingness to play within these rules. The different positions are relevant for the discussion of children's play activities supported by digital technologies because although children's participation in this context occurs in the virtual world, the positions still contribute to understanding children's play scenarios. In addition, sustaining friendships has been extended to a virtual world. Social relationships are the foundation for children's learning and development as they participate in their particular culture (Vygotsky, 1998). Therefore, using a cultural-historical approach to examine children's interaction using digital technologies provides us with analytical tools to understand the child's social situation of development, including children's demands and intentions as they participate in imaginative activities and connect in virtual worlds in the context of COVID-19 social distancing measures.

This paper brings together conceptual understandings established between cultural-historical theoretical positioning and the value of digital technologies in children's everyday life during the covid-19 lockdown. These are presented here to highlight the potential moving forward as children are placed in a position where face to face contact may not be possible. Through using this particular conceptual lens to inform the methodology, it is possible 
to better understand the emotional, imaginary and social engagement that children experience as they negotiate digital technology, which contributes to understanding children's learning and development during the lockdown of 2020.

\section{Methodology}

A cultural-historical approach to visual methodology involves observing children in natural settings and everyday contexts (Fleer, 2014; Quinones, 2014). This study focused on friends connecting online at home and in a virtual world. Touchscreen play with iPads provides a dialogic method for understanding children's voices, for example, expressed nonverbally and through body language (Cao, 2020). Still visual images show patterns across data collection and can provide a detailed visual analysis (Fleer, 2014). Monk (2014) explains that visual images help families with dialogue around their everyday practices and values. Visual images with narratives provide opportunities to reveal motives (intentions) and ideas that are important for understanding cultural practices (Ridgway, 2014). Further, in the current study, the researchers also adopts affective positioning by being part of the everyday life of children. That is, the first author documented over time the friendship between Silvia and Zara, the two focus children in the current study. Ethical consent followed university protocols where both parental and the children's consent was sought to use the images and words included in this study. The participants were informed they could withdraw their consent at any time.

\subsection{Study Context}

Silvia and Zara live in Australia. They are both the only children in their respective families. They are close friends and when they were both seven years of age, they regularly made drawings of their close relationship (e.g. Figure 1).

Their friendship began when they were attending kindergarten when they were both three years of age, and they maintained close contact over the following two years. However, the parents enrolled the children in different primary schools. The children often asked their parents if they could FaceTime with each other or meet over the weekend for a play date.

In 2020 when the COVID-19 pandemic took effect, friends could no longer see each other. However, the parents and children remained in contact with each other via Facebook and MSN Kids, an online platform designed for children that allows them to chat (see https://messengerkids.com/how-it-works/). 


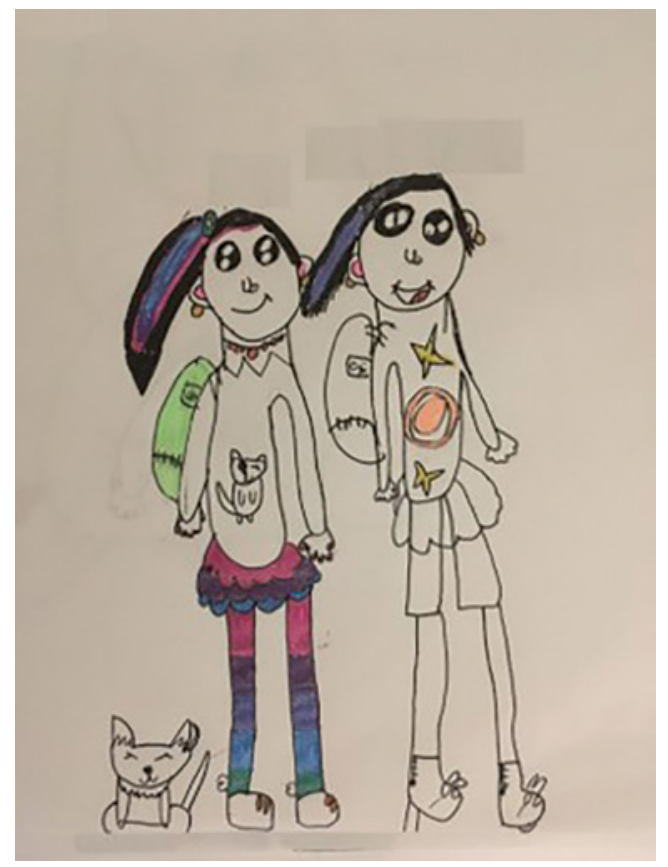

FIGURE 1

Drawing of Silvia's drawing of her friendship

The findings reported in this study reveal periods of virtual learning. In Victoria, the first lockdown occurred from mid-March to June 2020 and the second one from July to September 2020. The lockdown periods provided an opportunity for children to connect virtually with each other via online platforms (e.g. parents' iPhones and iPads for FaceTime and a digital flip camera for recording), where they creatively explored their friendship in a virtual world.

\section{4} Findings

This section presents the discussion on the friends' attunement with each other in the virtual world during Covid-19. The findings focus on the two lockdown periods. In the first lockdown period, Silvia and Zara created opportunities to participate in imaginary performances, adopting roles in play and supporting each other. In the second lockdown period, the children participated in virtual games, where they learned how to engage with different apps. 


\subsection{First Lockdown: Opportunities for Imaginary Performances}

In the first lockdown, Silvia chatted with friends approximately four to five times per week, they called each other from their mothers' mobile telephone or tablet telephone. Silvia's mother provided a digital flip camera to document everyday life at home. Silvia decided to record and direct videos and invited Zara to perform. In the first lockdown, Silvia produced 47 videos that ran for an average of one and a half minutes each.

The following vignette presents an example of Silvia directing Zara's performance and Zara completing an improvised performance.

\section{Vignette 1}

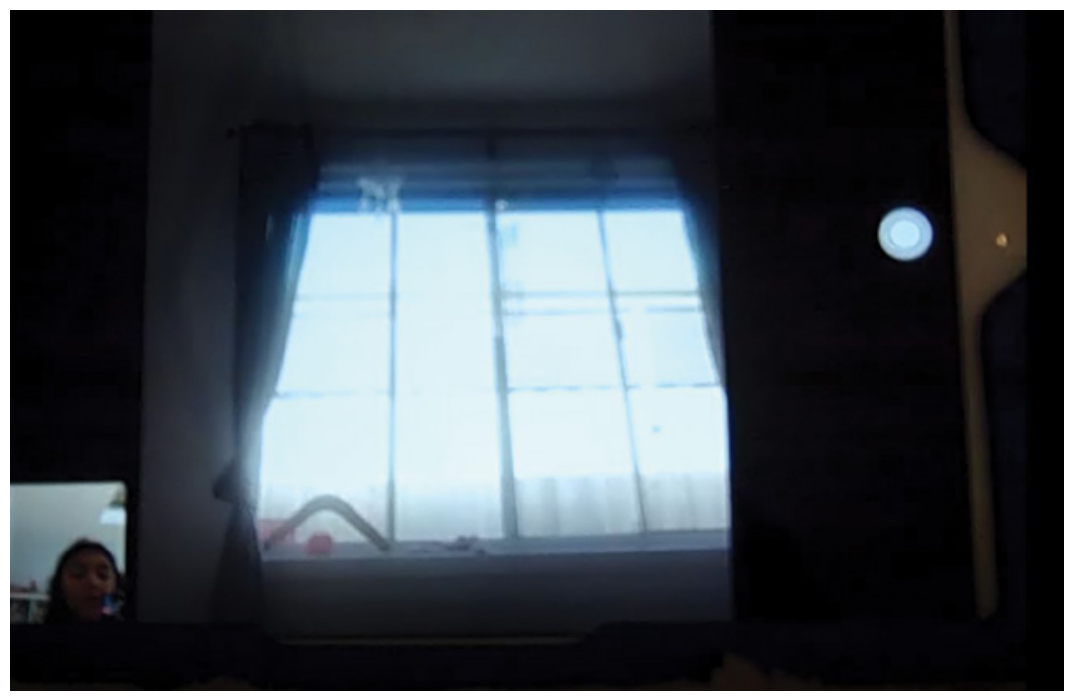

FIGURE 2 Silvia directing Zara (Silvia on left side waiting for Zara to appear)

Silvia is holding her digital flip camera towards the table.

In an enthusiastic voice, Silvia states, 'Zara is going to perform a wonderful song that will break your heart into little pieces. She is going to make up a song and sing it, sing it, sing it, sing it. Ok ready? She is going to start now!! Start!' (Figure 2).

Zara begins to sing and dance, 'Ta ta ta, I am a little mouse. I like to eat cheese, I still eat even though I get a stomach ache.'

Zara dances and touches her belly: 'Stomach ache, stomach ache and look there is a birdy. I made a little birdy, it's ripping, oh no it's dead'.

Zara drops the bird: 'I still eat even though I get a stomach ache.' 
Zara keeps dancing and singing: 'I am a mouse. I eat cheese and bread; I dig, I am a mouse.'

Silvia stops the video recording.

In Vignette 1, Silvia and Zara created an imaginary situation, and an improvised performance. The visual technology provided what Vygotsky (1998) refers to as a social situation of development. However, this was a new reality for the children, and this new reality supported learning about each other's individual and social characteristics and promoted their experimentation with different ways to engage in an online world.

The virtual role play involved creating an imaginary situation (Vygotsky, 1966), which although improvised, was familiar to Silvia and Zara because they had recorded videos in the past. When adding the new technology of the digital flip camera, Silvia identified herself in the 'director's role' and introduced Zara to the performance (Kravtsov \& Kravtsova, 2010). Silvia directed and introduced Zara's performance: 'Zara is going to perform a wonderful song that will break your heart into little pieces. She is going to make up a song and sing it, sing it, sing it, sing it. Ok ready? She is going to start now!! Start!' Zara indicated attunement with Silvia, who encouraged Zara to perform. Zara sang and created a motive orientation towards her performance, adopting the role of a mouse. Hedegaard (2020) argues that children's orientation to the world is located in forces originating from the surrounding world. In this instance, the pandemic was an all-encompassing force that in combination with parental support created the conditions for the children to interact online and use technology to capture their improvised imaginary role play.

In the children's imaginary situation, the real, imaginary and virtual worlds become their surrounding environment and a source of learning and development. Silvia and Zara collectively attuned themselves to their new social situation, connecting virtually as friends. Zara is responsive to Silvia's directions and is able to remember her everyday experiences expressed in lines such as 'I still eat [cheese] even though I get a stomach ache.' In her everyday life, when Zara eats cheese, she gets a stomach ache. Zara dances and identifies herself with a non-human animal, the mouse. In Zara's imaginary situation, she adopts the role of a mouse and this activity provides her with the opportunity to humorously sing about her own likes - eating cheese although she cannot do this in reality. Zara makes fun of her stomach ache by creating an improvised plot. Zara sings, 'I am a mouse. I eat cheese and bread; I dig, dig, I am a mouse.'

The children's perspective involves intentional actions as together, they responsively participate in and merge the real, imaginary and virtual worlds. Hedegaard (2020) explains how children's intentional actions provide an important picture of children's social situations. Children develop their motives 
and engagements in activities, and they can support and oppose their own initiatives and activities. Silvia and Zara support each other's imaginary performances in the virtual world and show creative attunement towards each other.

\subsection{Second Lockdown: Opportunities for Virtual Games}

In the second lockdown, children's social situations changed because they had access to MSN Kids, an online social media platform for children that allows parents to supervise their children online through parental control and monitoring functions. Hedegaard (2020) explains that parents play an important role in shaping children's lives and futures by creating the conditions for activities. This was certainly the case for children's virtual connection during the second lockdown in which their parents provided them with the use of MSN Kids. The parents supported the children to engage online by downloading the program, and adding the children's friends to the platform to access the chat function. The MSN Chat also provided more freedom for Zara and Silvia to engage in virtual text and visual literacy such as written conversations in which they used emojis, words and played virtual games.

Parents considered the children's chats a private space however they did monitor and have access to their chats. Virtual games were used for play and fun, improvisation and learning about choices and preferences. These virtual games were played individually. However, the children made their separate game playing into a collaborative, shared activity as they sent each other images of scores, images of themselves playing and an image with an invitation to participate in the game. One game that children played was Sushi Cat (Figure 3), which involves eating spaghetti virtually and selecting decorative elements such as hats. All the games involved taking a 'selfie' after the game finished and provided the option of sharing the 'selfie' with a friend.

In the virtual game named Sushi Cat, Silvia dressed up in the virtual world and adopted the role of a cat in the role of a chef. When children play this game, they are provided with thirty seconds to create many plates with virtual ingredients (e.g. salmon, tuna, egg, shrimp, rice and seaweed). The game provides prompts for children to make sushi plates. For example, rice and salmon or rice and tuna. Children locate the ingredients to make the plates and they receive points for each plate. Games involve adhering and playing with rules (Kratsov \& Kratsova, 2010). Digital technologies provided children the time and space to follow the virtual rules and imagine creating new roles, such as being a cat chef, all documented through selfies and saved on the digital tablets. Digital technologies provide a platform for saving children's representations and narratives (Wernholm \& Reneland-Forsman, 2019). The 'selfies' visually revealed their emotions through exaggerated nonverbal gestures, for example, 


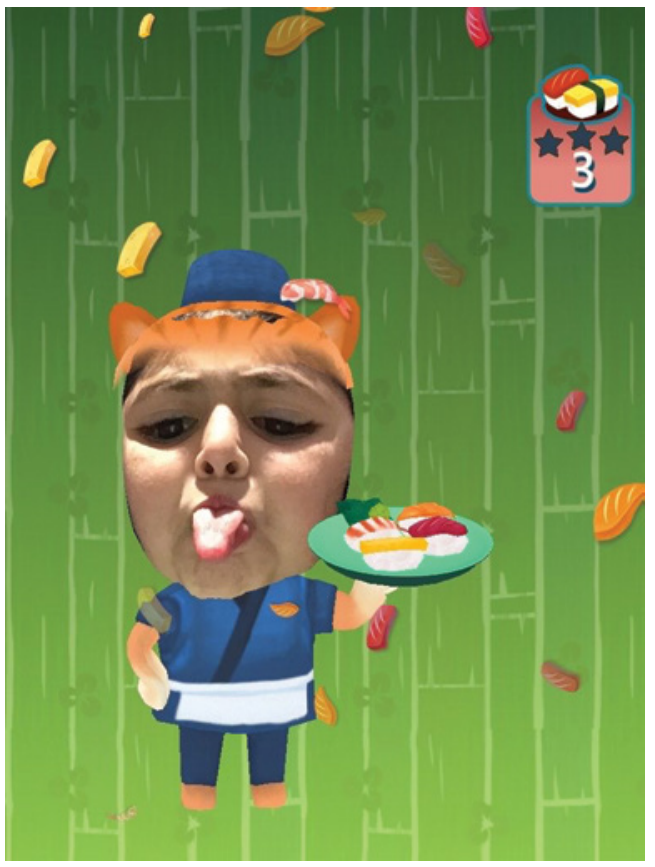

FIGURE 3

Silvia 'selfie' of virtual game

Silvia sticking out her tongue. Children were attuned to each other emotionally and virtually by sending each other 'selfies' and sharing their score.

The virtual games provided opportunities for new imaginary and virtual roles such as being a Sushi Chef. The different embodied role represents a new experience while playing a virtual game. We argue virtual games with a chat function create conditions for individual plays and collaborative interaction, which provide opportunities for children to develop new demands and motives in a virtual world. As discussed by Fleer (2020), games with rules involve collective participation by following rules and being attuned to and with each other. In games, children are usually willing to abide by the rules (Kravtsov \& Kravtsova, 2010), therefore this study argues that virtual games not only involve a willingness to play, but also teach children to follow set rules. This is different from face-to-face imaginary play where children improvise and invent, agree and disagree, and negotiate the rules of the play, which may or may not be connected to their everyday reality (Adams \& Quinones, 2020). The games in the virtual world provided the opportunity to follow the rules to obtain a score, where children can virtually and visually share scores through 'selfies' that form part of the unwritten rules and expectations of the game. Virtual games include fun and anticipation while waiting to receive a score. However, the 
focus on scores may bring a competitive aspect to the game; this was a positive aspect as it was about sharing.

\section{Discussion}

The current study argues that because of Covid-19, young children have been launched into learning about, and experiencing a virtual world. The online space shows great potential for building and maintaining social connections, and for contributing to children's learning and development. Many children's social situations changed and their relationships shifted to the virtual world because of the challenges created by the social distancing measures imposed due to the Covid-19 pandemic. Using a cultural-historical approach, the current study extends the literature to focus on children maintaining friendships and using digital technology. It was found that digital technology was a tool used for sharing and negotiating imaginary performances and playing virtual games together using a variety of devices and platforms. To avoid children becoming socially isolated because of the strict mandates that accompanied social distancing, the parents in the current study enabled the children's use of different digital technologies. As Fleer (2020) states, a collective social situation of development involves family attunement. Fleer's (2020) discussion focuses on family members being involved in playing games and providing opportunities for young children's engagement with visual technology in a virtual world. This study shows the importance of digital technology in children's lives while being isolated from physically seeing their friends. Digital technologies are social tools that can be used for building a collective social situation of development and maintaining friendships.

Hedegaard (2020) argues that parents play an important role in shaping children's lives and futures by creating the conditions for their activities. The children's parents created conditions such as accessing and downloading the technology, providing time, space and privacy, as well as encouraging children to engage in shifting their face-to-face friendship to connect through a range of online and digital technologies. Rather than contributing to a sense of moral panic (Walker et al., 2018), in the current study, the parents actively encouraged and enabled the children's virtual connection. The children were actively supported to develop a new motive orientations towards using digital technologies, through which they were provided with opportunities to stay connected with each other despite being socially or physically distanced. The parents provided their children with both the freedom and time to explore their own virtual worlds. The virtual world created by the children involved 
imaginary performances and virtual games that extended their collective social situations of development.

The child's perspective involves children's intentions and intentional actions when they participate in activities. Children develop a motive orientation to and engagement in activities, which supports the continuation of their activities (Hedegaard, 2020). From the perspective of children, the activities undertaken the use of digital technologies were a tool for engagement with virtual worlds, connecting with friends and digital technologies enabled emotive connections with each other. The intentions and actions were collaborative because they supported each other's initiatives through which they could explore, experiment, direct, create imaginary roles and play virtual games.

In conclusion, this study contributes data that reports on children's use of digital technologies and the internet (Kardefelt-Winther et al., 2019). The data captured a unique aspect of mandated social distancing where social contact for two primary school age friends moved to the online space. With different digital technologies, the two focus children were able to maintain their friendship and explore imaginary and creative play while adopting different roles in the play. Virtual worlds provide children the opportunity to build on imaginary spaces, which contributed to sustaining their friendship through emotional and visual connection. Digital technologies is a significant learning tool that allows children to create a collective social situation of development that integrates imaginary, real and virtual worlds, within the virtual games. The children followed the rules of the game, which is different from what may occur in some face-to-face play. Rather than negotiating and making their own rules as the play progressed, the rules of the game were already set by the game designers. However, the combination of real, imaginary and virtual worlds supported the children to experience an array of emotions such as joyous moments, empathy and attunement as they encouraged each other to participate in the virtual world and maintain their friendship connection.

Implications arising from this research indicate that digital technologies create a new motive orientation for children to spend time in a virtual world. Children's relations within the virtual world and to their friends needs further exploration, for example how each child contributes to their own development, by taking on different roles such as a director and or performer. 
More research is needed to understand how children interact with virtual worlds and the potential learning it brings to their everyday lives. Digital technologies provide a space for the development of children's friendships and peer relations. The virtual world provides a place to learn, negotiate and explore imaginary worlds and everyday knowledge, from the child's perspective.

\section{Acknowledgements}

Thank you to the participants for sharing their virtual worlds.

\section{References}

Adams, M., \& Quinones, G. (2020). Collaborative pathways to friendship in early childhood: A cultural-historical perspective. Abingdon: Routledge. https://www.doi.org/ 10.4324/9780203728925.

Aarsand, P., \& Aronsson, K. (2009). Gaming and territorial negotiations in family life. Childhood, 16, 497-517. https://www.doi.org/10.1177/0907568209343879.

Bjork-Willen, P., \& Aronsson, K. (2014). Preschoolers' “animation” of computer games. Mind, Culture, and Activity, 21(4), 318-336.

Canning, N., Payler, J., Horsley, K. \& Gomez, C. (2017). An innovative methodology for capturing young children's curiosity, imagination and voices using a free app: Our Story. International journal of Early Years Education, 25(3), 292-307.

Cao, K. (2020). Competing voices: Hidden dialogicity through visual encounters with children's play with touchscreen devices. In J. White (Ed.), Seeing the world through children's eyes. Visual methodologies and approaches to research in the early years (pp. 72-95). Leiden: Brill.

Corsaro, W. A. (1985). Friendship and peer culture in the early years. Indiana: Ablex Publishing Corporation.

Corsaro, W. \& Molinari, L. (2000). 'Priming events and Italian children's transition from preschool to elementary school: Representations and actions.' Social Psychology Quarterly, 63(1), 16-33.

Danby, S., Davidson, C., Ekberg, S., Breathnach, H., \& Thorpe, K. (2016). 'Let's see if you can see me': Making connections with Google Earth in a preschool classroom. Children's Geographies, 14(2), 141-157. https://www.doi.org/10.1080/14733285.2015.112 6231.

Davies, J. (2012). Facework on Facebook as a new literacy practice. Computers \& Education, 59(1), 19-29. https://www.doi.org/10.1016/j.compedu.2011.11.007. 
Davidson, \& M. Hatzigianni (Eds.) (2018). Digital childhoods: technologies and children's everyday lives. Singapore: Springer. https://www.doi.org/10.1007/978-981-10 -6484-5_6.

Fan, S., \& Yost, H. (2019). Keeping connected: Exploring the potential of social media as a new avenue for communication and collaboration in early childhood education. International Journal of Early Years Education, 27(2), 132-142. https://www.doi.org/1 0.1080/09669760.2018.1454301.

Fleer, M. (2014). Beyond developmental geology: A cultural-historical theorization of digital visual technologies for studying young children's development. In M. Fleer \& A. Ridgway (Eds.), Visual methodologies and digital tools for researching with young children transforming visuality (pp. 15-34). Cham: Springer. https://www.doi.org/ 10.1007/978-3-319-01469-2_2.

Fleer, M. (2019). A collective social situation of development for understanding play in families. In A. Edwards, M. Fleer, \& L. Bøttcher (Eds.), Cultural-historical approaches to studying learning and development: Societal, institutional and personal perspectives (pp. 53-67). Singapore: Springer. https://www.doi.org/10.1007/978-981 $-13-6826-4 \_4$.

Fleer, M. (2020). Digital pop-ups: Studying digital pop-ups and theorising digital popup pedagogies for preschools. European Early Childhood Education Research Journal, 28(2), 214-230. https://www.doi.org/10.1080/1350293X.2020.1735741.

Furman, M., De Angelis, S., Dominguez Prost, E., \& Taylor, I. (2019). Tablets as an educational tool for enhancing preschool science. International Journal of Early Years Education, 27(1), 6-19. https://www.doi.org/10.1080/09669760.2018.1439368.

Hedegaard, M. (2020). Children's perspectives and institutional practices as keys in a wholeness approach to children's social situations of development. Learning, Culture and Social Interaction, 26. https://www.doi.org/10.1016/j.lcsi.2018.04.008.

Hedegaard, M., \& Fleer, M. (2008). Studying children: A cultural-historical approach. New York: Open University Press.

Kardefelt-Winther, D., Livingstone, S., \& Saeed, M. (2019). Growing up in a connected world (Research report). Retrieved from UNICEF Office of Research-Innocenti: https://www.unicef-irc.org/publications/1060-growing-up-in-a-connected-world .html.

Kewalramani, S., \& Havu-Nuutinen, S. (2019). Preschool teachers' beliefs and pedagogical practices in the integration of technology: A case for engaging young children in scientific inquiry. EURASIA Journal of Mathematics, Science and Technology Education, 15(12), 1-13. https://www.doi.org/10.29333/ejmste/109949.

Kravtsov, G. G., \& Kravtsova, E. E. (2010). Play in L. S. Vygotsky's nonclassical psychology. Journal of Russian and East European Psychology, 48(4), 25-41. https://www.doi .org/10.2753/RPO1061-0405480403. 
Monk, H. (2014). Intergenerational family dialogues: A cultural historical tool involving family members as co-researchers working with visual data. In M. Fleer \& A. Ridgway (Eds.), Visual methodologies and digital tools for researching with young children transforming visuality (pp. 73-88). Cham: Springer. https://www.doi.org/ 10.1007/978-3-319-01469-2_5.

Quinones, G. (2014). A visual and tactile path: Affective positioning of researcher using a cultural-historical visual methodology. In M. Fleer \& A. Ridgway (Eds.), Visual methodologies and digital tools for researching with young children transforming visuality (pp. 111-128). Cham: Springer. https://www.doi.org/10.1007/978-3-319-01469 -2 -7.

Quinones, G. \& Adams, A. (May, 2020). CoviD-19 The Importance of young children making virtual connections Monash Lens. https://lens.monash.edu/2020/05/ o6/1380266/covid-19-the-importance-of-young-children-becoming-virtualfriends.

Rizzi, T., \& Corsaro, W. (1995). Social support processes in early Childhood friendship: A comparative study of ecological congruences in enacted support. American Journal of Community Psychology, 23(3), 289-471.

Ridgway, A. (2014). The Past-Present Dialectic: A New Methodological for Seeing the Historical Dynamic in Cultural-Historical Research. In M. Fleer \& A. Ridgway (Eds.), Visual methodologies and digital tools for researching with young children transforming visuality (pp. 55-72). Cham: Springer. https://www.doi.org/10.1007/978-3-319 -01469-2_4.

Sulaymani, O., Fleer, M. \& Chapman, D. (2018). Understanding children's motives when using iPads in Saudi classrooms: is it for play or for learning? International Journal of Early Years Education, 26(4), 340-353.

Sheer, V. C. (2011). Teenagers' use of MSN features, discussion topics and online friendship development: The impact of media richness and communication control. Communication Quarterly, 59(1), 82-103. https://www.doi.org/10.1080/01463373.2010 .525702 .

Swist, T., Collin, P., McCormack, J. \& Third, A. (2015). Social media and the wellbeing of children and young people: A literature review. Perth, WA: Prepared for the Commissioner for Children and Young People, Western Australia.

Vygotsky, L. S. (1966). Play and its role in the mental development of the child. Voprosy Psikhologii (Psychology Issues), 12(6), 62-76.

Vygotsky, L. S. (1998). The collected works of L. S. Vygotsky (Vol. 5): Child Psychology. New York: Plenum Press.

Vygotsky, L. S. (2004). Imagination and creativity in childhood. Journal of Russian and East European Psychology, 42(1), 7-97. https://www.doi.org/10.1080/10610405.2004.11 059210. 
Walker, S., Hatzigianni, M., \& Danby, S. J. (2018). Electronic gaming: associations with self-regulation, emotional difficulties and academic performance. In S. Danby, M. Fleer, C. Davidson, \& M. Hatzigianni (Eds.) Digital childhoods: Technologies and children's everyday lives (pp. 85-100). Springer, Singapore.

Wernholm, M. \& Reneland-Forsman, L (2019). Children's representation of self in social media communities. Learning, Culture and Social Interaction, https://www.doi .org/10.1016/j.lcsi.2019.100346.

Whitehead, L. (2017). Social and emotional development in the digital age. Building emotional literacy Exchange. July/August. www.childcareexchange.com.

Yelland, N. \& Gilbert, C. (2018). Transforming technologies and play in the early years: Using tablets for new learning. Global Studies of Childhood, 8(2), 152-172. 